\section{SAT0144 EFFECT OF AGING ON BONE MASS AND SKELETAL MUSCLE MASS IN ELDERLY PATIENTS WITH RHEUMATOID ARTHRITIS: TOMORROW STUDY}

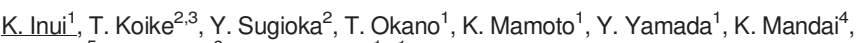
M. Tada ${ }^{5}$, H. Nagata ${ }^{6}$, H. Nakamura ${ }^{1}{ }^{1}$ Department of Orthopaedic Surgery, ${ }^{2}$ Center for Senile Degenerative Disorders (CSDD), Osaka City University Graduate School of Medicine, Osaka, ${ }^{3}$ Search Institute for Bone and Arthritis Disease (SINBAD), Shirahama Hamayu Hospital, Wakayama, ${ }^{4}$ Department of Orthopaedic Surgery, Osaka Social Medical Center Hospital, ${ }^{5}$ Department of Orthopaedic Surgery, Osaka City General Hospital, Osaka, ${ }^{6}$ Department of Orthopaedic Surgery, Shiraniwa Hospital, Nara, Japan

Background: Both osteoporosis and sarcopenia are common in patients with chronic inflammatory conditions such as rheumatoid arthritis (RA). Fragility fractures occur on osteoporotic bone on falling. Unstable gait caused by sarcopenia increases the frequency of such falls.

Objectives: To evaluate the relationship between bone mineral density (BMD) and appendicular skeletal muscle index (ASMI) in patients with RA and healthy controls.

Methods: We used data collected over a 7-year period from 2010 to 2016 as part of a prospective cohort study (TOMORROW Study: UMIN000003876) that included RA patients and age- and sex-matched volunteers recruited through mass media as controls. BMD of the lower leg and ASMI were determined using whole-body dual-energy X-ray absorptiometry. These were collected for all participants together with baseline characteristics including anthropometric data and blood test data related to lipid and sugar metabolism. Each parameter for the RA patients was compared with that for the healthy controls. Multiple regression analysis was carried out in the RA population only. In RA patients, treatment regimen and disease activity score 28 were recorded.

Results: Among 413 participants of the TOMORROW Study (208 RA patients; 349 women; mean age 58 years), 137 participants age 65 years or older (77 RA; 117 women) were enrolled in the present study. BMD and ASMI decreased significantly over the 7-year study period in RA patients and healthy controls from baseline. BMD and ASMI were lower in RA patients than in healthy controls at every time point through the 7-year study period. There was no interaction between time and RA ( $p=0.194,0.089$; repeated measure ANOVA). The change of BMD at year 7 from baseline $(\triangle \mathrm{BMD})$ and change of ASMI at year 7 from baseline $(\triangle \mathrm{ASMI})$ did not correlate in health controls, however, in RA patients, $\triangle \mathrm{BMD}$ correlated positively with $\triangle \mathrm{ASMI}(\mathrm{r}=0.331, \mathrm{p}=0.023)$ ( $\mathrm{Fig})$. Multiple regression analysis with $\triangle \mathrm{BMD}$ as the outcome variable and anti-citrullinated peptide antibody, Rheumatoid factor, ASMI, body mass index, disease activity score 28 , homeostatic model assessment (HOMA)-R, Matrix metalloprotease (MMP)-3 and sex as independent variables revealed that male sex $(p=0.0036)$ and ASMI $(p=0.0020)$ were independently related with $\triangle B M D$.

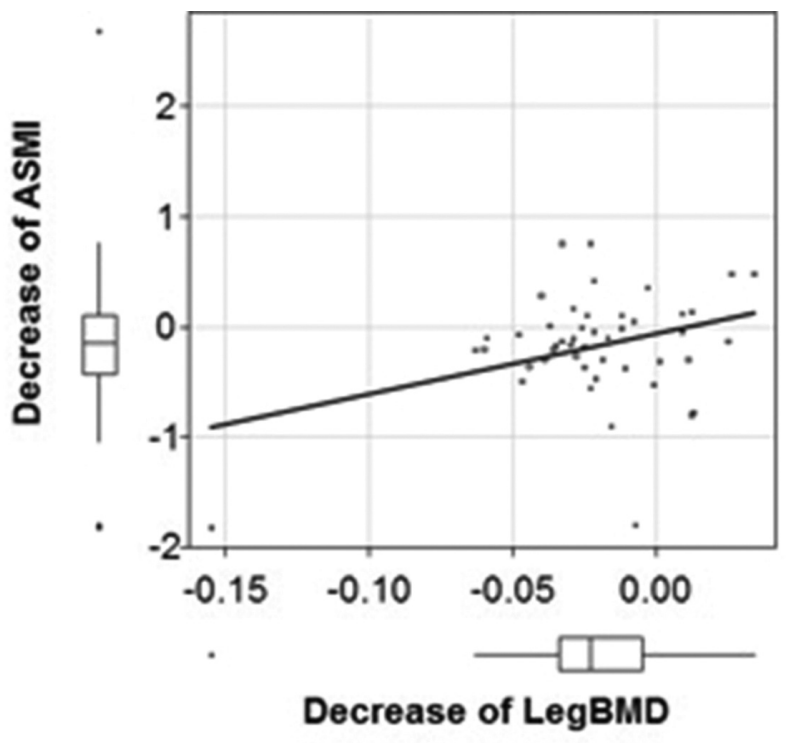

Figure 1 Correlation between change of ASMI and BMD for 7 years in elderly patients with RA.(pearson correlation coefficient; $r=0.331, P=0.0229$ )

Conclusions: Decrease of BMD and ASMI were correlated with each other in elderly patients with RA.

Disclosure of Interest: None declared

DOI: 10.1136/annrheumdis-2018-eular.1780

\section{SAT0145 FEATURES OF PATIENTS WITH RHEUMATOID ARTHRITIS WHOSE DEBUT JOINT IS A FOOT OR ANKLE JOINT: A 5,479 CASES STUDY FROM THE IORRA COHORT}

K. Yano ${ }^{1}$, K. Ikari ${ }^{1}$, K. Okazaki ${ }^{2}$, A. Taniguchi ${ }^{1}$, H. Yamanaka ${ }^{1} .{ }^{1}$ Institute of Rheumatology, ${ }^{2}$ Orthopedic Surgery, Tokyo Women's Medical University, Tokyo, Japan

Background: Foot and ankle joint disorders are serious issues for patients with rheumatoid arthritis (RA). Rheumatoid foot is reported as the first symptom of the disease in $20-53 \%$ of RA patients ${ }^{1-3}$. However, there are few studies investigating the features of patients with RA whose debut joint is a foot or ankle joint.

Objectives: The aim of this study is to compare the differences between RA patients whose first symptom was a foot or ankle joint (FOOT group) and was other joints (OTHER group) by using the Institute of Rheumatology, Rheumatoid Arthritis (IORRA) cohort in our institute.

Methods: In the IORRA survey conducted in April 2016, patients were asked about first symptom at RA onset. Disease activities, clinical laboratory variables, functional disability, quality of life, and the use and ratio of anti-inflammation and anti-rheumatic drugs were compared between the FOOT group and OTHER group.

Results: Among 5,637 Japanese patients with RA who participated in the IORRA survey on April 2016, 5,479 patients (97.2\%) responded to the questionnaire regarding debut joint. Of these 5,479 patients, $2,402(43.8 \%)$ reported their first symptom of RA were a foot or ankle. Comparing the two groups, the FOOT group had higher disease activity, higher disabilities, lower quality of life, low activities of daily living, and poorer mental health and used higher dose and rate of anti-inflammatory drugs significantly than the OTHER group (all $P<0.01$ ). On the other hand, medications to suppress the disease activity of RA have no statistical differences between the two groups (table 1).

Table 1 Comparison of clinical features and outcomes between the FOOT group and the OTHER group

\begin{tabular}{llll}
\hline & $\begin{array}{l}\text { FOOT group } \\
(\mathrm{n}=2,164)\end{array}$ & $\begin{array}{l}\text { OTHER group } \\
(\mathrm{n}=2,164)\end{array}$ & $\mathrm{P}$ \\
\hline DAS28 & $2.82 \pm 1.1(0.0-7.0)$ & $2.51 \pm 0.95(0.0-6.1)$ & $<0.01$ \\
CRP, mg/dl & $0.44 \pm 0.92(0.0-9.7)$ & $0.32 \pm 0.80(0.0-18.3)$ & $<0.01$ \\
RF, IU/ml & $118.5 \pm 260.7(3-$ & $97.2 \pm 217.1(3-5544)$ & $<0.01$ \\
& $7150)$ & & \\
J-HAQ & $0.69 \pm 0.76(0-3)$ & $0.47 \pm 0.66(0-3)$ & $<0.01$ \\
EQ5D & $0.78 \pm 0.18(-0.1-1.0)$ & $0.85 \pm 0.2(0.1-1.0)$ & $<0.01$ \\
NSAID use, no. (\%) & $1,162(53.7)$ & $972(44.9)$ & $<0.01$ \\
PSL use, no. (\%) & $659(30.5)$ & $569(26.3)$ & $<0.01$ \\
PSL dose, mg/day & $1.17 \pm 2.3(0-18)$ & $0.9 \pm 2.0(0-15)$ & $<0.01$ \\
DMARD use, no. (\%) & $1,926(89.0)$ & $1,921(88.8)$ & 0.85 \\
MTX use, no. $(\%)$ & $1,671(77.2)$ & $1,656(76.5)$ & 0.61 \\
MTX dose, mg/week & $6.18 \pm 4.8(0-17.5)$ & $5.88 \pm 4.7(0-20)$ & 0.059 \\
Biologic DMARD use, no. & $495(22.9)$ & $458(21.2)$ & 0.19 \\
(\%) & & & \\
\hline
\end{tabular}

Conclusions: Patients whose debut joint was a foot or ankle had higher disease activity, higher dysfunction, lower quality of life, and used higher dose and rate of anti-inflammatory drugs than patients whose debut joint was the other joints on RA onset. Clinicians should have more attentions to foot and ankle joints in daily practice so as not to underestimate the disease activity of RA

\section{REFERENCES}

[1] Grondal L, Tengstrand B, Nordmark B, Wretenberg P, Stark A. The foot still the most important reason for walking incapacity in rheumatoid arthritis: distribution of symptomatic joints in 1,000 RA patients. Acta Orthop 2008:79:257-61.

[2] Otter SJ, Lucas K, Springett K, Moore A, Davies K, Cheek L, et al. Foot pain in rheumatoid arthritis prevalence, risk factors and management: an epidemiological study. Clin Rheumatol 2010;29:255-71.

[3] Vainio K. The rheumatoid foot; a clinical study with pathological and roentgenological comments. Ann Chir Gynaecol Fenn Suppl 1956;45:1-107.

Disclosure of Interest: K. Yano Speakers bureau: Bristol-Meyers, Pfizer, Eisai, Tanabe-Mitsubishi, Chugai, AbbVie, Janssen Pharmaceutical, Asahi-Kasei and Takeda., K. Ikari Grant/research support from: Astellas, UCB, Bristol-Meyers, Pfizer, Eisai, Tanabe-Mitsubishi, Chugai, AbbVie, Janssen Pharmaceutical, Otsuka, Kaken, Asahi-Kasei, Hisamitsu and Takeda., Speakers bureau: Astellas, UCB, Bristol-Meyers, Pfizer, Eisai, Tanabe-Mitsubishi, Chugai, AbbVie, Janssen Pharmaceutical, Otsuka, Kaken, Asahi-Kasei, Hisamitsu and Takeda., K. Okazaki: None declared, A. Taniguchi Grant/research support from: AbbVie, Eisai, Takeda, Speakers bureau: AbbVie, Eisai, Takeda, Tanabe-Mitsubishi, Teijin Pharma and Pfizer., H. Yamanaka Grant/research support from: MSD, Ayumi, AbbVie, Eisai, Ono, Astellas, Daiichi-Sankyo, Taisyo-Toyama, Takeda, Tanabe- 
Mitsubishi, Chugai, Teijin Pharma, Torii, Nippon Shinyaku, Pfizer. UCB. Nippon Kayaku, YL biologics, Bayer and Bristol-Meyers., Consultant for: MSD, Ayumi, AbbVie, Eisai, Ono, Astellas, Daiichi-Sankyo, Taisyo-Toyama, Takeda, TanabeMitsubishi, Chugai, Teijin Pharma, Torii, Nippon Shinyaku, Pfizer. UCB. Nippon Kayaku, YL biologics, Bayer and Bristol-Meyers., Speakers bureau: MSD, Ayumi, AbbVie, Eisai, Ono, Astellas, Daiichi-Sankyo, Taisyo-Toyama, Takeda, TanabeMitsubishi, Chugai, Teijin Pharma, Torii, Nippon Shinyaku, Pfizer. UCB. Nippon Kayaku, YL biologics, Bayer and Bristol-Meyers.

DOI: 10.1136/annrheumdis-2018-eular.1046

\section{SAT0146 AT DIAGNOSIS OF RHEUMATOID ARTHRITIS, AT-RISK PATIENTS FOLLOWED IN CCP+ CLINIC SHOWED MILDER DISEASE ACTIVITY THAN CONVENTIONALLY REFERRED PATIENTS.}

L. Duquenne ${ }^{1,2,{ }^{*}}$, P. Pentony ${ }^{1,2}$, K. Mankia ${ }^{1,2}$, J. Nam ${ }^{1,2}$, L. Hunt ${ }^{1,2}$, A. L. $\operatorname{Tan}^{1,2}$, L. Garcia-Montoya ${ }^{1,2}$, P. Emery ${ }^{1,2} .{ }^{1}$ Leeds Institute of Rheumatic and Musculoskeletal Medicine, University of Leeds, ${ }^{2}$ NIHR Leeds Biomedical Research Centre, Chapel Allerton Hospital, Leeds, United Kingdom

Background: Early treatment of rheumatoid arthritis (RA) improves clinical and radiological outcomes ${ }^{1}$. Risk stratification models can identify patients at high risk of developing $\mathrm{RA}^{2-5}$ which may lead to an extension of the window of opportunity. Whether identifying and following at-risk individuals improves outcomes after the development of RA however is yet to be determined.

Objectives: The hypothesis is that patients followed in a specific at-risk clinic will have less severe disease at diagnosis than those referred via the conventional route if/when they develop $R A$.

Methods: In two single-centre prospective observational cohorts, patients fulfilling the 2010 EULAR classification criteria for RA were compared on a demographic and clinical approach. The first group was composed of 59 patients positive for anti-cyclic citrullinated protein antibodies (CCP) with non-specific musculoskeletal symptoms, considered to be "at-risk of RA", who were followed until RA diagnosis. The second group was composed of 92 CCP positive RA patients referred to a standard 'Early Arthritis' rheumatology clinic.

Results: Demographic data at RA development were consistent between both groups including smoking history and BMI. Immunological features were also similar. CCP titre: at risk median 193U/ml (IQR 41,300), standard care 300U/ml (IQR $81,300, \mathrm{p}=0.176)$ ). Rheumatoid factor (RF) titre: at risk median $84 \mathrm{iU} / \mathrm{mL}(\mathrm{IQR}$ $15,223)$, standard care $87 \mathrm{iU} / \mathrm{mL}$ (IQR18,161, $\mathrm{p}=0.850$ ). RF positivity: at risk $75 \%$, standard care $70 \%(p=0.544)$. High-titre CCP blood levels: at risk $95 \%$, standard care $97 \%(p=0.566)$.

As shown in table 1, DAS28CRP score were significantly lower in the at risk group than in standard care, this was due to a difference in the general health Visual Analogue Scale score and the CRP levels. Patients in the at risk group also had fewer swollen large joints and reported significantly shorter time between onset of subjective joint swelling and diagnosis. There was no difference between the presence of erosions on ultrasound scans (at risk: $39 \%$, standard care $38 \%$, $\mathrm{p}=0.921)$.

\begin{tabular}{llll}
\hline & $\begin{array}{l}\text { At Risk of } \\
\text { RA }^{*}\end{array}$ & $\begin{array}{l}\text { Standard } \\
\text { care }^{*}\end{array}$ & $\begin{array}{l}\text { P- } \\
\text { value }\end{array}$ \\
\hline Age mean (SD) & 55.3 y $(12.6)$ & 56.4 y $(19.1)$ & 0.711 \\
Women & $73 \%$ & $71 \%$ & 0.815 \\
BMI mean (SD) & $28(5.4)$ & $27(6.5)$ & 0.299 \\
Ever smoker & $70 \%$ & $55 \%$ & 0.075 \\
DAS28CRP & $3.9(3.2,4.6)$ & $4.9(3.4,5.6)$ & 0.003 \\
TJC28 & $5(3,9)$ & $7(2,14)$ & 0.447 \\
SJC28 & $2(1,5)$ & $4(2,9)$ & 0.001 \\
GH VAS & $41(18,64)$ & $57(37,75)$ & 0.003 \\
CRP & $5.4(0,11)$ & $26(18,49)$ & 0.000 \\
HAQ & $10(2,17)$ & $12(5,20)$ & 0.197 \\
Large joint swelling mean (SD) & $0.14(0.4)$ & $0.39(0.7)$ & 0.014 \\
Weeks before subjective Swelling to RA & $6(2,12)$ & $29(16,52)$ & 0.00
\end{tabular}

diagnosis

${ }^{*}$ Median (IQR) unless specified

Conclusions: Patients who were diagnosed with RA while being followed in an at-risk cohort had milder disease activity and less pain than those diagnosed through standard referral despite equivalent demographics and serology. This reflects an earlier diagnosis and hence shorter exposure to inflammation. Followup will be required to see if these differences convert to long-term benefits.

\section{REFERENCES:}

[1] van der Heide. Ann Intern Med 1996;124(8).

[2] Rakieh. Ann Rheum Dis 2015;74(9)

[3] Van de Stadt. Ann Rheum Dis 2013;72(12).

[4] Van Steenbergen. Ann Rheum Dis 2016;75(10).

[5] Nam JL. Ann Rheum Dis 2016;75(12).
Disclosure of Interest: None declared

DOI: 10.1136/annrheumdis-2018-eular.5704

\section{SAT0147 PRESENCE OF HEPATITIS B VIRUS IN SYNOVIUM AND ITS CLINICAL SIGNIFICANCE IN RHEUMATOID ARTHRITIS}

L.-J. Yang ${ }^{1}$, Y.-L. Chen ${ }^{1}$, J. Jing ${ }^{1}$, Y.-Q. Mo ${ }^{1}$, J.-D. Ma ${ }^{1}$, L.-F. Chen ${ }^{1}$, J.-Z. Lin ${ }^{1}$, Z. H. Yang ${ }^{2}$, T. Yan ${ }^{3}$, D.-H. Zheng', F. Pessler ${ }^{4,5}$, L. Dai'. ${ }^{1}$ Department of Rheumatology, ${ }^{2}$ Department of Radiology, Sun Yat-sen Memorial Hospital, Sun Yat-sen University, ${ }^{3}$ Zhongshan School of Medicine, Sun Yat-sen University, Guangzhou, China, ${ }^{4}$ TWINCORE Center for Experimental and Clinical Infection Research, Hannover, ${ }^{5} \mathrm{Helmholtz}$ Center for Infection Research, Braunschweig, Germany

Background: Previous studies have shown that hepatitis B virus (HBV) infection may be associated with rheumatoid arthritis (RA). However, no study regarding the presence of HBV in the synovial membrane from RA patients has been reported.

Objectives: To investigate the presence of HBV in RA synovium and determine its influence on histopathological characteristics of synovitis as well as clinical and radiographic outcomes in $R A$.

Methods: 57 consecutive patients with active RA (DAS28-CRP $\geq 2.6$ ) and qualified synovium (at least 6 pieces of synovial tissues per patient, containing lining layer and sublining area) obtained by closed Parker-Pearson needle biopsy who had completed one year follow-up were retrospectively recruited from a prospec tive RA cohort $(n=239)$. The patients were divided into chronic HBV infection ( $\mathrm{CHB}$, positive HBsAg and/or HBV DNA in serum persisting for over 6 months; $\mathrm{n}=11$ ), resolved HBV (negative HBsAg and HBV DNA in serum, but positive anti$\mathrm{HBc} ; \mathrm{n}=22$ ), and non-HBV (negative $\mathrm{HBsAg}, \mathrm{HBeAg}$, anti-HBe, anti-HBc, and HBV DNA in serum, regardless of anti-HBs; $n=24$ ) groups according to baseline HBV infection status. Clinical data were collected at baseline and follow-up visits at months $1,3,6$, and 12. Radiographic assessments of hand/wrist at baseline and month 12 were performed with the Sharp/van der Heijde-modified sharp score (mTSS). Serial tissue sections were stained immunohistochemically for $\mathrm{HBsAg}$, HBcAg, CD3, CD15, CD20, CD34, CD38, and CD68. Nested PCR was used to detect HBV $S$ gene DNA in synovium.

Results: Immunohistochemical staining and nested PCR revealed the presence of $\mathrm{HBcAg}$ and $\mathrm{S}$ gene DNA in the synovium from RA patients with $\mathrm{CHB}$ (figure 1). Compared with the non-CHB group $(n=46)$, significantly more CD15-positive neutrophils, CD20-positive B cells, and CD68-positive macrophages infiltrated the $\mathrm{CHB}$ synovium (all $\mathrm{p}<0.05$ ), together with smaller improvements from baseline in most disease activity indicators mainly at month 12 . A significantly higher percentage of $\mathrm{CHB}$ patients experienced one-year radiographic progression ( $\Delta$ mTSS $>0.5$ units/year, $64 \%$ vs. $26 \%, p=0.024)$. Multivariate logistic regression analysis showed that $\mathrm{CHB}$ status (OR: $14.230,95 \% \mathrm{Cl}: 2.213-95.388 ; \mathrm{p}=0.006$ ) and the total count of CD68-positive macrophages (OR: $1.002,95 \% \mathrm{Cl}: 1.001-$ $1.003 ; p=0.003)$ were independently associated with one-year radiographic progression.

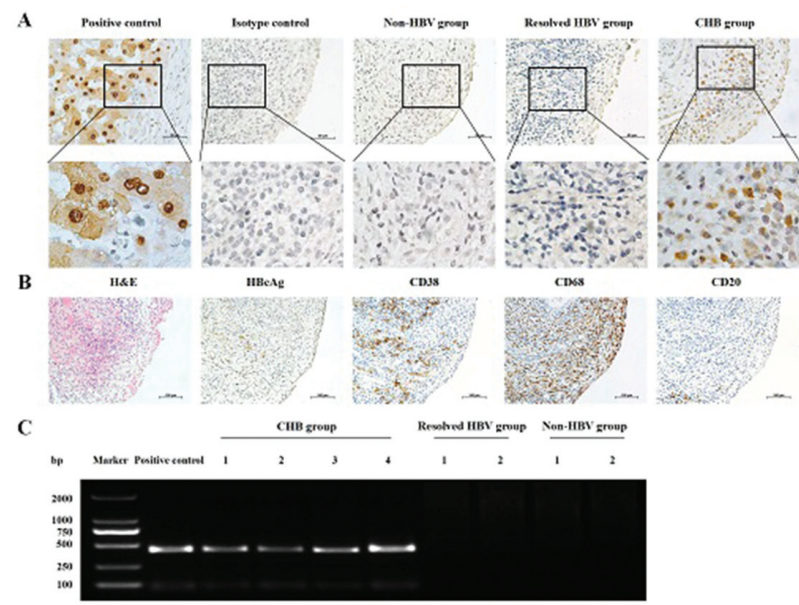

Figure 1 Identification of HBV in RA synovium. (A) Representative immunohistochemical staining for $\mathrm{HBcAg}$ in RA synovium. Representative images illustrated detection of $\mathrm{HBcAg}$ in a RA patient with $\mathrm{CHB}$, but not in RA patients with resolved $\mathrm{HBV}$ or no infection. (B) Representative staining of HBCAg in one RA patient with CHB compared to stains for CD38 and CD68. Serial sections of synovium from one RA patient with $\mathrm{CHB}$ were stained with $\mathrm{H} \& \mathrm{E}$ and immunohistochemically. $\mathrm{HBcAg}$ immunoreactivity was 